\title{
Grade of Service (GoS) Analysis on PT XYZ Using SolarWinds Orion
}

\author{
Novrizen \\ Informatics and Computer Engineering \\ Jakarta State Polytechnic \\ Depok, Indonesia \\ novrizen.tik15@mhsw.pnj.ac.id
}

\begin{abstract}
PT XYZ offered very high availability of network connections (Service Level Agreements or SLA) to customer requirements. The immense SLA offered by the company must be supported with good service quality of the internal network and proper maintenance scheduling. One of the parameters that can be used to measure internal network quality is Grade of Service (GoS). However, there's never been any analysis done on PT XYZ's internal network using this parameter so the quality of internal services not yet determined. In this study, Grade of Services (GoS) analysis was conducted on PT XYZ's internal network to find out whether the service quality of the internal network was in a good category based on the GoS value parameter. The analysis is carried out by utilizing the bandwidth usage data samples taken from one of the main nodes monitored by SolarWinds Orion. The bandwidth usage rate was analyzed in the period of days, weeks, and months to calculate network traffic volume so that the highest network traffic intensity trend and Grade of Service (GoS) value at the busiest hour can be determined. After 6 months of data collection, the intensity of network traffic at the busiest hour was obtained at 18.70 Erlang with a GoS value of $0.0000000001778 \%$. The GoS value shows that that service quality is in a very good state (below < 1\%) so network efficiency improvements not necessary at the moment.
\end{abstract}

Keywords-Grade of Service, SolarWinds Orion, Network Traffic Volume, Network Traffic Intensity.

\section{INTRODUCTION}

Do you know that most of IT service provider company guarantees the availability of network connections (SLA) almost $100 \%$ to their customers? In PT XYZ, the SLA offered is between $99 \%, 99.9 \%$ and $99.99 \%$ according to the needs of its customers [1]. The very high Service Level Agreement (SLA) offered by a company must be supported by the company's internal network with good service quality. One of the parameters that can be used to measure internal network quality is Grade of Service (GoS). A Grade of Service (GoS) is calculated from the perspective of the resource element as a network source provider. A grade of Service $(\mathrm{GoS})$ is important both as the actual quality of services measurement offered to customers and also as a level of service design parameter so that the traffic offered to customers is identical to the traffic carried or provided by resources [2]. However, analysis with Grade of Service (GoS) parameters has never been done on PT XYZ's internal network [3]. Thus far it hasn't known yet whether the quality of internal network services is in a good category if it viewed from the GoS value parameter.

Based on the background mentioned above, a Grade of Services (GoS) analysis was carried out on the PT XYZ by utilizing bandwidth usage data samples taken from one of the main nodes monitored by SolarWinds Orion. The level of bandwidth usage itself can be used to determine network traffic volumes so that the highest network traffic intensity trend and Grade of Service (GoS) value at the busiest hour can be determined. The value of Grade of Service (GoS) can be a benchmark whether the quality of the company's internal network (resource) currently provided is still directly proportional to the SLA offered by PT XYZ to customers.

\section{LITERATURE REVIEW}

\section{A. Basic Network Traffic}

Traffic is the transfer of information signals from one place to another through telecommunications media. The traffic unit commonly used is Erlang, which is taken from the name of a Danish scientist, Agner Kraup Erlang (1878-1929), an inventor of traffic theory. 1 Erlang is the occupation of a circuit that is continuous for 1 hour. The amount of traffic is the object of measuring the number of occupations on an equipment/channel measured by the time [4]. The amount of traffic known is:

1) Traffic Volume (V) = Total occupation time (Hours)

2) Traffic Intensity $(\mathrm{A})=$ Total occupation time per unit time (Erlang).

The network traffic volume can be determined by dividing the total bandwidth in the observation period with the average bit rate of each channel, with the equation as follows.

$$
\text { Traffic Volume }=\frac{\text { Total Bandwith }}{\text { Average Bit Rate }}
$$

Then the value of network traffic intensity can be obtained using the following equation.

$$
\text { Traffic Intensity }=\frac{\text { Traffic Volume }}{\text { Observation Period }}
$$

\section{B. Erlang-B Algorithm}

Erlang determines the level of service (Grade of Service) on a Lost Call System that has N channels with the traffic offered. The probability of a missing call is the first Erlang distribution and is called Grade of Service (GoS) or Erlang-B. To facilitate the calculation of GoS values, scripts can be used with the Matlab programming language obtained from the following equation [4, p. 131].

Erlang-B equation:

$$
\mathrm{B}=\mathrm{E}_{1, \mathrm{~N}}(\mathrm{~A})=\frac{\mathrm{AE}_{1, \mathrm{~N}-1}(\mathrm{~A})}{\mathrm{N}+\mathrm{AE}_{1, \mathrm{~N}-1}(\mathrm{~A})}
$$


Matlab scripts:

$$
\begin{aligned}
& \text { function } \mathrm{B}=\text { erlangb }(\mathrm{N}, \mathrm{A}) \\
& \mathrm{N}=\text { input }(\mathrm{N}=\text { ') } \\
& \mathrm{A}=\text { input }(\mathrm{A}=\text { ') } \\
& \mathrm{B}=1 ; \\
& \text { for } \mathrm{k}=1: \mathrm{N}, \\
& \mathrm{B}=((\mathrm{A} * \mathrm{~B}) / \mathrm{k}) /(1+\mathrm{A} * \mathrm{~B} / \mathrm{k}) \\
& \text { end; }
\end{aligned}
$$

Descriptions:

$$
\begin{array}{ll}
\text { E1, N } & =\text { Grade of Services (\%) } \\
\mathrm{N} & =\text { Number of Channels / Interfaces } \\
\mathrm{A} & =\text { Traffic Intensity (Erlang) } \\
\mathrm{B} & =\text { Erlang-B Algorithm Equation }
\end{array}
$$

The smaller the GoS value, the better the service. The recommended GoS value in Indonesia (Telkom) is 0.01 or $1 \%$ meaning that one call fails every 100 calls coming. While the GoS value that exceeds $1 \%$ means the possibility of network services is not good [4, p. 125].

\section{Network Protocol}

Protocol is a rule that must be understood by devices that will communicate. The protocol allows data to be sent and received parts per section to obtain a reliable transmission, then the data is rearranged according to the original data once it arrives at the destination. The process of rearranging the order of data at this destination is called reassembly. When data is to be transmitted, the protocol is responsible for maintaining the integrity of communication between the sending and receiving devices [5].

\section{Simple Network Management Protocol (SNMP)}

Simple Network Management Protocol (SNMP) is a network management protocol used to exchange information between hosts on a network that includes network monitoring software. SNMP is the most widely used protocol for managing and monitoring a network consisting of components, namely: Managed Device, Agent, and Network Management System (NMS). SNMP data is collected or sent to managed devices, either by polling or using traps. Trap allows agents to send information to NMS about events that occur on these devices [6].

\section{E. Internet Control Message Protocol (ICMP)}

Internet Control Message Protocol (ICMP) is a protocol that is useful in getting the status of a network device by sending special messages that later the network device will send a reply message. In the context of normal network devices, computers can carry out operations by utilizing communication infrastructure. But there are some conditions where the network connection is interrupted, for example because the computer crashes, the communication link breaks, or the network device is off. In this situation, the ICMP protocol helps to get status from network devices by sending requests to the destination device. If the device is in good condition, it will respond to the message, so the monitoring computer can conclude that the device is running normally [7].

\section{F. SolarWinds Orion}

SolarWinds Orion monitors network health and performance through ICMP, SNMP, WMI, API and Syslog communications and collects the data. The SolarWinds Orion platform includes two servers, namely:

1) Main Orion Server, which is the server where SolarWinds Orion is installed. The main server consists of Main Polling Machine and Orion Web Console.

2) A separate server where the database is installed from SolarWinds Orion.

The Polling Engine will request real-time statistics through polling methods such as SNMP or WMI from monitored devices. The results of the polls are then further processed and stored in the SolarWinds Orion database. Furthermore, the data that has been issued will be transferred to the Orion Web Console [6].

\section{METHOD}

PT XYZ uses SolarWinds Orion to monitor the performance of each node (server, router, and switch) that is connected to the company's network. In this study, the analysis was based only on the core router which connects the head office with branch offices. The analysis is done by taking the bandwidth usage data generated from SolarWinds, which is the total bytes received from each interface on the core router with a period of time per month, per week, and per day. This data then is used to calculate the volume and intensity of traffic from the network being analyzed. While the basic variables used to calculate the volume and intensity of PT XYZ's network traffic are as follows.

1) Number of interfaces on the core router: 56

\section{2) Average bandwidth for each Interfaces: $0.125 \mathrm{~GB} / \mathrm{s}$}

The bandwidth usage data were taken for 6 months starting from April 2018 to September 2018. First, the volume and intensity of network traffic was calculated using equation (1) and (2) in the monthly period to determined one month with the highest network traffic intensity. In this one month, the volume and intensity of network traffic is calculated in the weekly period to determine one week with the highest intensity of traffic. During this one week, the network traffic volume and intensity also being calculated to determine one busiest day and forth to determine the busiest hour on that day. After that, The GoS value during 6 months of observation period is determined with the Erlang-B equation using Matlab by inputting the number of interfaces and traffic intensity of the busiest hour.

\section{RESUlTS}

\section{A. Monthly Network Traffic Analysis}

The data used to analyze monthly network traffic is core router bandwidth usage data for each interface in one month. This data is a sample taken from SolarWinds Orion during 6 months starting from April 2018 to September 2018, with an observation period of 720 hours (for April, June, September) and 744 hours (for May, July, August). The bandwidth usage, network traffic volume, and network traffic intensity are shown in the table below. 
TABLE I. MONTHLY NETWORK TRAFFIC DATA

\begin{tabular}{|c|c|c|c|}
\hline Monthly Period & $\begin{array}{c}\text { Total } \\
\text { Bandwidth } \\
\text { Usage }\end{array}$ & $\begin{array}{c}\text { Traffic } \\
\text { Volume } \\
\text { (Hour) }\end{array}$ & $\begin{array}{c}\text { Traffic } \\
\text { Intensity } \\
\text { (Erlang) }\end{array}$ \\
\hline April 2018 & $25.99 \mathrm{~TB}$ & 3548.66 & 4.93 \\
\hline May 2018 & $25.74 \mathrm{~TB}$ & 3514.92 & 4.72 \\
\hline June 2018 & $22.96 \mathrm{~TB}$ & 3134.25 & 4.35 \\
\hline July 2018 & $26.65 \mathrm{~TB}$ & 3639.03 & 4.89 \\
\hline August 2018 & $24.22 \mathrm{~TB}$ & 3307.07 & 4.44 \\
\hline September 2018 & $\mathbf{3 7 . 6 5}$ TB & $\mathbf{5 1 3 9 . 3 7}$ & $\mathbf{7 . 1 4}$ \\
\hline
\end{tabular}

In TABLE I shows that the highest traffic intensity occurs in September 2018 with a value of 7.14 Erlang, while the lowest traffic intensity occurs in June 2018 with a value of 4.35 Erlang.

\section{B. Weekly Network Traffic Analysis}

The data used to analyze weekly network traffic is core router bandwidth usage data for each interface in one week. This data is a sample taken for 4 weeks (from day 1 to 28) in one month, starting from April 2018 to September 2018. It is known that September was the busiest month but all the other months also being calculated weekly to make sure the result is concrete. The bandwidth usage, network traffic volume, and network traffic intensity is shown in the table below.

TABLE II. WEEKLY NETWORK TRAFFIC DATA

\begin{tabular}{|c|c|c|c|c|}
\hline Month & $\begin{array}{l}\text { Weekly } \\
\text { Period }\end{array}$ & $\begin{array}{c}\text { Total } \\
\text { Bandwidth } \\
\text { Usage }\end{array}$ & $\begin{array}{l}\text { Traffic } \\
\text { Volume } \\
\text { (Hour) }\end{array}$ & $\begin{array}{c}\text { Traffic } \\
\text { Intensity } \\
\text { (Erlang) }\end{array}$ \\
\hline \multirow{4}{*}{$\begin{array}{l}\text { April } \\
2018\end{array}$} & Week 1 & $6.67 \mathrm{~TB}$ & 911.07 & 5.42 \\
\hline & Week 2 & $5.69 \mathrm{~TB}$ & 776.97 & 4.62 \\
\hline & Week 3 & $6.16 \mathrm{~TB}$ & 841.45 & 5.01 \\
\hline & Week 4 & $5.87 \mathrm{~TB}$ & 801.51 & 4.77 \\
\hline \multirow{4}{*}{$\begin{array}{l}\text { May } \\
2018\end{array}$} & Week 1 & $5.98 \mathrm{~TB}$ & 815.90 & 4.86 \\
\hline & Week 2 & $5.35 \mathrm{~TB}$ & 729.92 & 4.34 \\
\hline & Week 3 & $5.74 \mathrm{~TB}$ & 783.59 & 4.66 \\
\hline & Week 4 & $6.29 \mathrm{~TB}$ & 859.16 & 5.11 \\
\hline \multirow{4}{*}{$\begin{array}{l}\text { June } \\
2018\end{array}$} & Week 1 & $5.45 \mathrm{~TB}$ & 744.49 & 4.43 \\
\hline & Week 2 & $5.76 \mathrm{~TB}$ & 786.52 & 4.68 \\
\hline & Week 3 & $4.72 \mathrm{~TB}$ & 644.83 & 3.84 \\
\hline & Week 4 & $5.58 \mathrm{~TB}$ & 762.43 & 4.54 \\
\hline \multirow{4}{*}{$\begin{array}{l}\text { July } \\
2018\end{array}$} & Week 1 & $6.05 \mathrm{~TB}$ & 825.99 & 4.92 \\
\hline & Week 2 & $5.98 \mathrm{~TB}$ & 816.12 & 4.86 \\
\hline & Week 3 & $6.04 \mathrm{~TB}$ & 824.05 & 4.91 \\
\hline & Week 4 & $5.88 \mathrm{~TB}$ & 802.23 & 4.78 \\
\hline \multirow{5}{*}{$\begin{array}{c}\text { August } \\
2018\end{array}$} & Week 1 & $4.74 \mathrm{~TB}$ & 646.97 & 3.85 \\
\hline & Week 2 & $5.96 \mathrm{~TB}$ & 813.83 & 4.84 \\
\hline & Week 3 & $5.27 \mathrm{~TB}$ & 720.09 & 4.29 \\
\hline & Week 4 & $5.48 \mathrm{~TB}$ & 747.66 & 4.45 \\
\hline & Week 1 & $6.67 \mathrm{~TB}$ & 910.15 & 5.42 \\
\hline
\end{tabular}

\begin{tabular}{|c|c|c|c|c|}
\hline $\begin{array}{c}\text { September } \\
2018\end{array}$ & Week 2 & $\mathbf{9 . 2 5}$ TB & $\mathbf{1 2 6 2 . 3 8}$ & $\mathbf{7 . 5 1}$ \\
\cline { 2 - 5 } & Week 3 & 8.87 TB & 1211.68 & 7.21 \\
\cline { 2 - 5 } & Week 4 & 8.98 TB & 1226.51 & 7.30 \\
\hline
\end{tabular}

In TABLE II shows that the highest traffic intensity occurs in the $2^{\text {nd }}$ week of September 2018 with a value of 7.51 Erlang, while the lowest traffic intensity occurs in the $3^{\text {rd }}$ week of June 2018 with a value of 3.84 Erlang.

\section{Daily Network Traffic Analysis}

The data used to analyze network daily traffic is core router bandwidth usage data for each interface in a day. This data is a sample taken for 30 days starting from September 1, 2018, at 12:00 AM until September 30, 2018, at 12:00 AM. The bandwidth usage, network traffic volume, and network traffic intensity are shown in the table below.

TABLE III. DAILY NETWORK TRAFFIC DATA

\begin{tabular}{|c|c|c|c|}
\hline Day & $\begin{array}{c}\text { Total } \\
\text { Bandwidth } \\
\text { Usage (GB) }\end{array}$ & $\begin{array}{l}\text { Traffic } \\
\text { Volume } \\
\text { (Hour) }\end{array}$ & $\begin{array}{l}\text { Traffic } \\
\text { Intensity } \\
\text { (Erlang) }\end{array}$ \\
\hline 1 September 2018 & 553.87 & 73.85 & 3.08 \\
\hline 2 September 2018 & 506.68 & 67.56 & 2.81 \\
\hline 3 September 2018 & 826.36 & 110.18 & 4.59 \\
\hline 4 September 2018 & 716.62 & 95.55 & 3.98 \\
\hline 5 September 2018 & 1188.4 & 158.45 & 6.60 \\
\hline 6 September 2018 & 1711.51 & 228.20 & 9.51 \\
\hline 7 September 2018 & 1373.07 & 183.08 & 7.63 \\
\hline 8 September 2018 & 966.7 & 128.89 & 5.37 \\
\hline 9 September 2018 & 937.74 & 125.03 & 5.21 \\
\hline 10 September 2018 & 1587.29 & 211.64 & 8.82 \\
\hline 11 September 2018 & 774.54 & 103.27 & 4.3 \\
\hline 12 September 2018 & 1821.94 & 242.93 & 10.12 \\
\hline 13 September 2018 & 1757.33 & 234.31 & 9.76 \\
\hline 14 September 2018 & 1728.83 & 230.51 & 9.6 \\
\hline 15 September 2018 & 893.93 & 119.19 & 4.97 \\
\hline 16 September 2018 & 1053 & 140.4 & 5.85 \\
\hline 17 September 2018 & 1352.98 & 180.4 & 7.52 \\
\hline 18 September 2018 & 1390.73 & 185.43 & 7.73 \\
\hline 19 September 2018 & 1421.5 & 189.53 & 7.9 \\
\hline 20 September 2018 & 1509.52 & 201.27 & 8.39 \\
\hline 21 September 2018 & 1583.29 & 211.11 & 8.8 \\
\hline 22 September 2018 & 836.67 & 111.56 & 4.65 \\
\hline 23 September 2018 & 832.51 & 111 & 4.63 \\
\hline 24 September 2018 & 1425.05 & 190.01 & 7.92 \\
\hline 25 September 2018 & 1673.24 & 223.1 & 9.3 \\
\hline 26 September 2018 & 1658.75 & 221.17 & 9.22 \\
\hline 27 September 2018 & 1531.3 & 204.17 & 8.51 \\
\hline 28 September 2018 & 1411.13 & 188.15 & 7.84 \\
\hline 29 September 2018 & 1091.04 & 145.47 & 6.06 \\
\hline 30 September 2018 & 893.31 & 119.11 & 4.96 \\
\hline
\end{tabular}


In TABLE III shows that the highest traffic intensity occurred on 12 September 2018 with a value of 10.12 Erlang, while the lowest traffic intensity occurred on 2 September 2018 with a value of 2.81 Erlang.

\section{The Grade of Service (GoS)}

Grade of Services (GoS) value is calculated by observing the busiest hours of the day. In TABLE III shows that the biggest traffic intensity is on September 12, 2018 (10.12 Erlang). By calculating the bandwidth usage of all interfaces on the core router every hour, the busiest hours of the day are at 4:00 PM. At this hour, the total bandwidth usage was 140.22 GB. Network traffic volume can be known by dividing the total bandwidth usage with an average Bitrate of $0.125 \mathrm{~GB} / \mathrm{s}$. For the network traffic intensity can be calculated by dividing the traffic volume with the observation period for 1 hour. The calculation of network traffic volume and intensity as follows.

1) Traffic Volume (V)

$$
\begin{aligned}
\mathrm{V} & =\frac{140.22 \mathrm{~GB}}{0.125 \mathrm{~GB} / \mathrm{s}} \\
& =1121.76 \mathrm{~s} \\
& =18.70 \text { hour }
\end{aligned}
$$

2) Traffic Intensity (A)

$$
\begin{aligned}
\mathrm{A} & =\frac{18.70 \text { hour }}{1 \text { hour }} \\
& =18.70 \text { Erlang }
\end{aligned}
$$

To calculate the GoS value, it can be done using the Erlang-B algorithm Matlab program. With the number of Interfaces of 56 and traffic intensity of 18.70 Erlang, the GoS value was $0.0000000001778 \%$.

\section{CONCLUSION}

The Grade of service (GoS) analysis was carried out on PT XYZ's internal network to find out whether the service quality of the internal network was in a good category based on the GoS value parameter. The analysis used the bandwidth usage data taken from one of the main nodes (core router) monitored by SolarWinds Orion from April 2018 to September 2018. After calculating the network traffic volume and intensity per month, week, and day, the result shows that September 2018 was the busiest month with the highest network traffic on September $12^{\text {th }}$. The intensity of network traffic at the busiest hour on that day was obtained at 18.70 Erlang and using Erlang-B Algorithm Matlab program, a GoS value was obtained at $0.0000000001778 \%$. The GoS value shows that that service quality was in a very good state and the quality of the company's internal network (resource) currently provided was still directly proportional to the SLA offered (below $<1 \%$ according to the Telkom Indonesia standard) so network efficiency improvements not necessary at the moment. In future analysis, more accurate results can be achieved by doing analysis with more extended observation period and not only based on core router but also branch routers and other nodes so the analysis data can be compared between nodes.

\section{REFERENCES}

[1] LPiK ITB, "Lintasarta dan LPIK ITB Gelar Appcelerate 2018," 2018. [Online]. Available: http://lpik.itb.ac.id/. [Accessed 8 Januari 2019].

[2] IBM, "IBM Knowledge Center - Erlang based functions," 2017. [Online]. Available: https://www.ibm.com/. [Accessed 8 Januari 2019].

[3] R. A. Setiawan, Interviewee, Analisis Grade of Service (GoS). [Interview]. 10 Januari 2019.

[4] J. Susilo, A. Hamzah and J. Triyono, "Analisis Dan Monitoring Traffic Kinerja Jaringan Wireless Local Area Network (WLAN) di Kantor Komunikasi dan Informatika (KOMINFO) Yogyakarta Menggunakan Aplikasi MRTG Berbasis SNMP," Jurnal JARKOM, vol. 5, no. 2, pp. 120-134, 2017.

[5] S. Handayani and P. T. Pungkasanti, "Monitoring dan Analisis Trafik di Jaringan USM Menggunakan Multi Router Traffic Grapher," JURNAL TRANSFORMATIKA, vol. 12, no. 1, pp. 1-6, 2014.

[6] SolarWinds, "Network Monitoring Basics - SNMP Basics | SolarWinds," 17 October 2018. [Online]. Available: https://www.solarwinds.com. [Accessed 17 Oktober 2018].

[7] A. Heryanto, A. Hermansyah and M. Nizar, "Sistem Monitoring Server dan Perangkat Jaringan Pada Enterprise Resource Planning FASILKOM UNSRI Menggunakan Protokol ICMP dan SNMP," Jurnal SISTEMASI, vol. 6, no. 3, pp. 1-10, 2017. 